\title{
Practical Methodology of the Integrated Design and Power Control Unit for SHEV with Multiple Power Sources
}

\author{
Seongjun Lee* and Jonghoon $\mathrm{Kim}^{\dagger}$
}

\begin{abstract}
Series hybrid electric vehicles (SHEVs) having multiple power sources such as an enginegenerator (EnGen), a battery, and an ultra-capacitor require a power control unit with high power density and reliable control operation. However, manufacturing using separate individual power converters has the disadvantage of low power density and requires a large number of power and signal cable wires. It is also difficult to implement the optimal power distribution and fault management algorithm because of the communication delay between the units. In order to address these concerns, this approach presents a design methodology and a power control algorithm of an integrated power converter for the SHEVs powered by multiple power sources. In this work, the design methodology of the integrated power control unit (IPCU) is firstly elaborately described, and then efficient and reliable power distribution algorithms are proposed. The design works are verified with product-level and vehicle-level performance experiments on a 10-ton SHEV.
\end{abstract}

Keywords: Integrated power control unit, Series hybrid electric vehicle, Power distribution algorithm, Energy storage system

\section{Introduction}

These days, hybrid electric vehicles are attractive as they are considered environment friendly in the context of global warming and other environmental issues [1-10]. Above all, the hybridization of mid- and heavy-sized vehicles has progressed, resulting in better fuel economy and higher performance [10]. Thus, there are many studies to improve the power and energy ratings of hybrid components such as the traction motor and the primary and secondary power sources, as well as studies aimed at new designs of these [11-16]. In particular, there has been research related to secondary sources that efficiently utilize multiple energy storage system (ESS) such as the battery and ultra-capacitor [17-19]. Unfortunately, a plurality of power converters for controlling the multiple power sources has the weaknesses of low power density inside the vehicle and the need for a large number of power and signal cable wires. In addition, it is difficult to implement optimal power distribution and fault management because of communication delay and signal errors caused by noise. These are major drawbacks of the series hybrid electric vehicles (SHEVs) having a high-voltage and high-power system.

In order to address these concerns, this approach deals with the design methodology and the power distribution algorithm of an integrated power converter of a series hybrid electric military vehicle powered by multiple power

$\dagger$ Corresponding Author: Dept. of Electrical Engineering, Chosun University, Korea. (whdgns0422@chosun.ac.kr)

* Research Center, Defense Program, Samsung Techwin, Korea. (jun2u@naver.com)

Received: March 12, 2015; Accepted: October 5, 2015 sources - two engine-generators (EnGens), a battery and an ultra-capacitor - as shown in Fig. 1. First, the interface functions of the designed integrated power control unit (IPCU) are analyzed, and then, the results of the thermal analysis conducted in order to achieve high power density and thermal stability during vehicle operation are described. In addition, we propose a power distribution algorithm based on the frequency of the load power that includes a rule-based method. The design approaches are verified by product-level and vehicle-level performance experiments on a 10 -ton SHEV.

The remainder of this approach is organized as follows. Section 2 describes the interface functions and the thermal analysis results of the IPCU. In the following Section 3, the controller design methods for the engine generator and secondary energy sources are described. The power distribution algorithm for the power system of the SHEV with multiple power sources is also proposed. Section 4 shows the product-level and vehicle-level experimental results with detailed experiments. In the final section, some conclusions and final remarks are given.

\section{Design Methodology of Integrated Power Control Unit (IPCU)}

The IPCU for the SHEVs in this work controls the power flow of the powertrain, consisting of the dual diesel EnGens, the ultra-capacitor and the battery as shown in Fig. 1. The IPCU consists of the 4-power stages such as two alternating current-direct current (AC-DC) pulse width modulation (PWM) converters and two bi-directional three- 


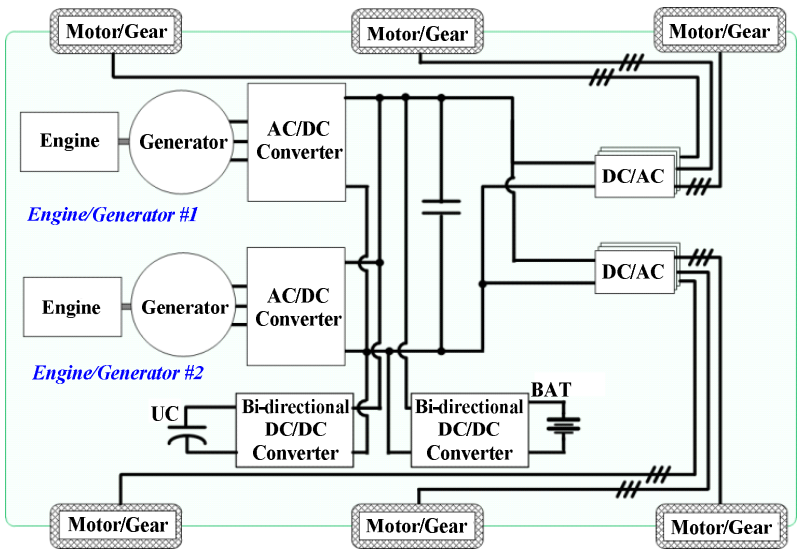

Fig. 1. 6x6 powertrain structure of the series hybrid electric vehicle (SHEV).

Table 1. Component characteristics of the integrated power control unit

\begin{tabular}{|c|c|}
\hline & Specifications \\
\hline $\mathrm{BCU}$ & $\begin{array}{l}\text { - Maximum power : } 100 \mathrm{~kW} \\
\text { - Input battery voltage : } 296 \mathrm{Vnom}\end{array}$ \\
\hline $\mathrm{UCU}$ & $\begin{array}{l}\text { - Maximum power : } 170 \mathrm{~kW} \\
\text { - Input ultra-capacitor voltage : } 250 \sim 500 \mathrm{~V}\end{array}$ \\
\hline GCU $1 / 2$ & $\begin{array}{l}\text { - Maximum generated power : } 100 \mathrm{~kW}(\mathrm{dc}-\text { side }) \\
\text { - Engine-generator speed : } 750 \sim 3600 \mathrm{rpm}\end{array}$ \\
\hline DC-Bus & $\begin{array}{l}\text { - High-side DC-link : } 640 \mathrm{Vdc} \\
\text { - Low-side ESS : 250 500 Vdc }\end{array}$ \\
\hline Cooling & $\begin{array}{l}\text { - Water cooled : } 15 \sim 22.5 \text { LPM } \\
\text { - Two input to output port pairs }\end{array}$ \\
\hline
\end{tabular}

Table 2. Interface functions of the integrated power control unit

\begin{tabular}{c|l}
\hline Source & \multicolumn{1}{c}{ Specifications } \\
\hline Engine/Generator \#1 & $\begin{array}{l}\cdot \text { ECM \#1 interfacing } \\
\cdot \text { Engine \#1 Warning/fault detection }\end{array}$ \\
\hline Engine/Generator \#2 & $\begin{array}{l}\cdot \text { ECM \#2 interfacing } \\
\cdot \text { Engine \#2 Warning/fault detection }\end{array}$ \\
\hline Battery & $\begin{array}{l}\cdot \text { DI/O for wakeup } \\
\cdot \text { BMS CAN-Network }\end{array}$ \\
\hline Ultra-capacitor & $\cdot$ DI/O for warning/fault detection \\
\hline
\end{tabular}

phase buck-boost converters. The design specifications, including the operating points of each source, are listed in Table 1.

The IPCU communications with the controller of each power source through digital and analog signals, as shown in Table 2. The interface configuration of the diesel EnGen consists of the speed regulation part that properly uses the accelerator position sensor (APS) of the engine control module (ECM), the ignition part of the ECM, and the alarm detection part for warning and fault events. The IPCU has the features required of the controller area network (CAN) communications, warning/fault detection, and circuits for the pre-charge operation and the highvoltage relay of the battery and the ultra-capacitor. The controllers and power distribution algorithms for each converter can be efficiently implemented by means of a digital signal processing (DSP)- and field programmable gate array (FPGA)-based platform implemented on a single control-board inside the IPCU. Therefore, it is possible to execute the algorithm related to control and fault diagnosis without any communication delay.

In order to achieve high power density and redundancy, a water-cooled heat sink with two pairs of inlet and outlet are employed. The heat sink is designed to absorb the heat generated from the switching and the concentration losses of the insulated gate bi-polar transistors (IGBTs) of the 4power stages, as shown in Fig. 2(a). The total of 12 IGBT half-bridge modules is spatially distributed in order to avoid the heat concentration on the heat sink. The losses in

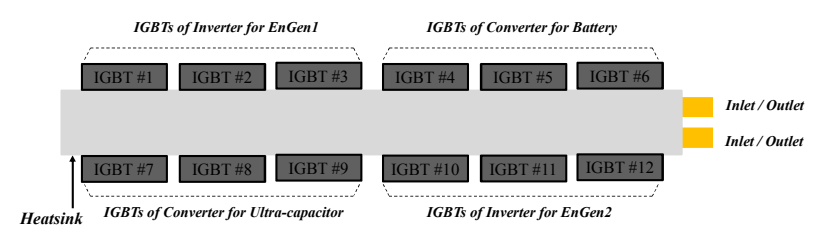

(a)

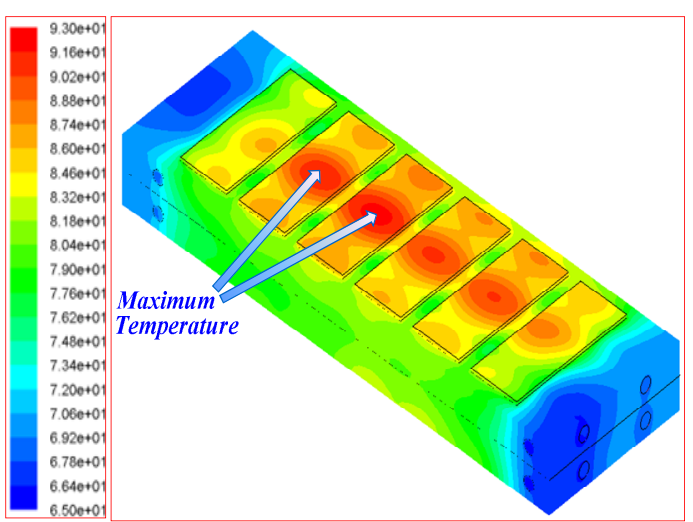

(b)

Fig. 2. Thermal features of water-cooled heat sink in the IPCU; (a) Thermal structure of the IPCU, (b) Thermal analysis of water-cooled heat sink.

the IPCU can be calculated from loss equations derived from the linearized current and voltage waveforms of the switching transition [20]. The losses may also be calculated from the conduction and switching loss energies provided by the manufacturer of the power semiconductor at certain specified operating points [21, 22]. To achieve thermal stability in the worst case, we utilized the road conditions of fast acceleration and high-speed operation of long durations to calculate the losses. Fig. 2(b) shows the result of the thermal analysis on top of the heat sink. It can be expected that the hot-spot temperature of the heat-sink was maintained below $95^{\circ} \mathrm{C}$ with a $65^{\circ} \mathrm{C}$ inlet coolant temperature during the maximum motoring operation of the power sources under paid acceleration of the vehicle. Therefore, the thermal requirement is satisfied. 


\section{Control Design of the IPCU}

\subsection{Controller design for three-phase bi-directional buck-boost converter}

In order to control the bi-directional power flow of the battery and the ultra-capacitor, a three phase bi-directional buck-boost converter of Fig. 3 is utilized, because of its relatively high efficiency and robustness of performance among non-isolation type topologies. For controlling the power flow and the state-of-charge (SOC) of the two energy storage units, the two-loop control, which includes the inner current and the outer voltage control-loop, is well chosen. Eq. (1) represents the small signal transfer function of the duty ratio to the inductor current $[20,23]$, derived from the small-signal modeling method [24, 25].

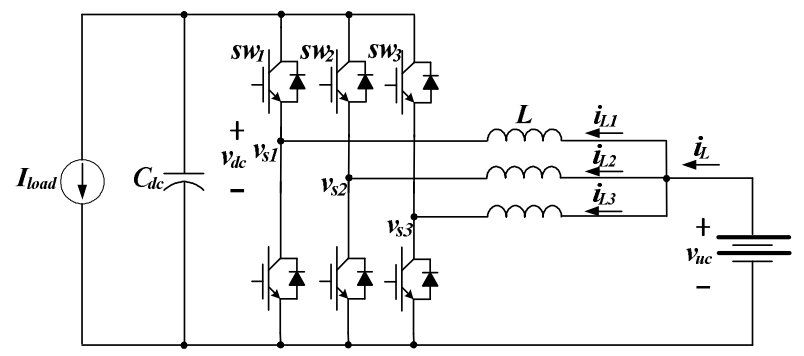

Fig. 3. Three-phase bi-directional buck-boost converter.

$$
\begin{gathered}
G_{i d}=\frac{2 V_{u c}}{D_{p}^{3} R} \frac{\left(1+R C_{d c} s / 2\right)}{\left(1+s / Q_{e q} / \omega_{o, e q}+s^{2} / \omega_{e q}{ }^{2}\right)} \\
\text { where, } L_{e q}=\frac{L}{3}, \omega_{o, e q}=\frac{D_{p}}{\sqrt{L_{e q} C_{d c}}}, \\
Q_{e q}=D_{p} / \omega_{o, e q}\left(L_{e q} / D_{p} R+R_{c, d c} C_{d c}\right)
\end{gathered}
$$

where $V_{u c}$ is the voltage of the ultra-capacitor, $R$ is the equivalent resistor related to the load power, $C_{d c}$ is the DClink capacitance, $D_{p}$ is the duty ratio of the boost converter such as $1-D, D$ is the duty ratio of the IGBT switch $S W_{1} \sim S W_{3}, Q_{e q}$ is the resonant frequency of the power stage transformed into the equivalent single-phase converter, $L_{e q}$ is the inductance of the equivalent single-phase power stage, and $R_{c, d c}$ is the internal series resistance of the DClink capacitor.

For stabilization of the inner current-loop, a proportional and integral (PI) controller is employed. After completing the current control-loop design, the transfer function of the current-loop closed plant is derived to design the voltage controller for DC-link voltage stabilization (Eq. (2)). For this purpose, assuming that the parameters of both the converters are almost the same, the transfer functions of the equivalent single power stage of the three parallelconnected boost converters can be employed [14]. As in the case of the current control loop, a PI controller is also employed. The parameters of the current and the voltage controller should be chosen to have a phase margin greater than $45^{\circ}$ and a gain margin greater than $6 \mathrm{~dB}$ over wide voltage and power ranges.

$G_{v d, e q}=\frac{V_{u c}}{D_{p}^{2}} \frac{\left(1+s / \omega_{z, e q}\right)\left(1-s / \omega_{a, e q}\right)}{\left(1+s / Q_{e q} \omega_{o, e q}+s^{2} / \omega_{o, e q}^{2}\right)}$

where, $\omega_{z, e q}=\frac{1}{R_{c, d c} C_{d c}}, \omega_{a, e q}=D_{p}{ }^{2} \frac{R}{L_{e q}}, \omega_{o, e q}=\frac{D_{p}}{\sqrt{L_{e q} C_{d c}}}$

Figs. 4 and 5 show the Bode diagram of the input current loop and the DC-link voltage loop gain, assuming that the DC-link voltage is controlled by the bi-directional converter power by the ultra-capacitor. In the case that the DC-link voltage is stabilized by the converter that has the battery as its input source, the current and voltage controller can be designed by applying the same approach. We can see that the loop gains of the designs have sufficient phase and gain margins over the input voltage and load power variations.

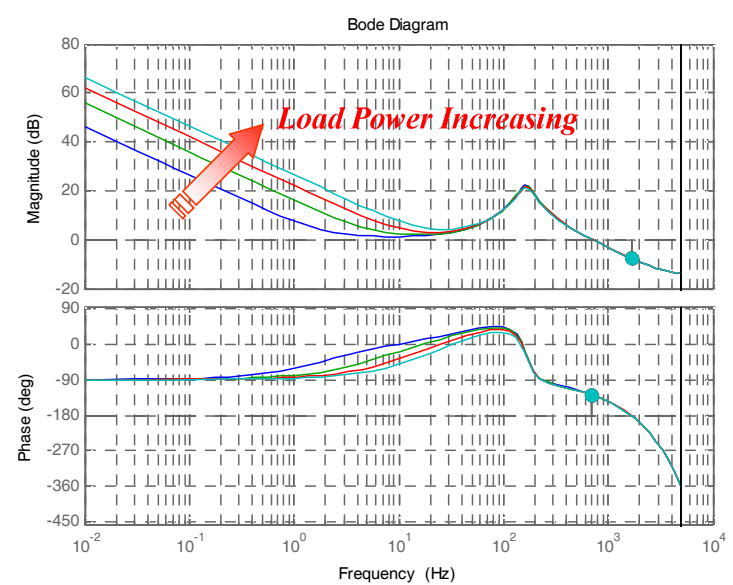

Fig. 4. Input current loop gain of bi-directional buck-boost converter.

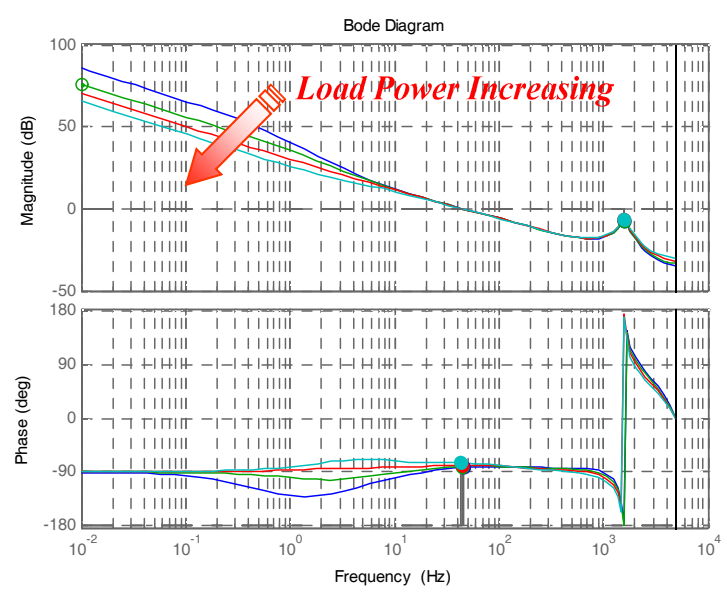

Fig. 5. DC link voltage loop gain of bi-directional buckboost converter. 


\subsection{Controller design for engine-generator (EnGen)}

Because the EnGen is decoupled from the driving wheels in the SHEV, the engine can be operated in the optimal fuel economy region regardless of vehicle speed. Therefore, an optimal operating line (OOL), considering both the fuel consumption of the engine and the efficiency of the generator, is chosen. Fig. 6 shows the brake specific fuel consumption (BSFC) and the established operating points on the speed-torque plane of the EnGen. The blue dotted line and the red dotted line indicate whether the goal is high efficiency or high performance respectively, as shown in Fig. 7. The speed and power slew-rate limit of the EnGen is determined by the control algorithm, using inputs such as the gear position, the mode button, the accelerator pedal, and the brake pedal. The mode button is used to implement the driver's choice, such as the high acceleration or high climbing performance mode.

Fig. 8 shows the control block diagram of the EnGen. In order to control the engine speed, the APS of the ECM is interfaced with the IPCU, and the generated power is controlled by means of the torque control of an interior permanent magnet (IPM) type generator. Specifically, the 1-D dimensional table for the speed reference related to the required power of the engine generator is derived from the

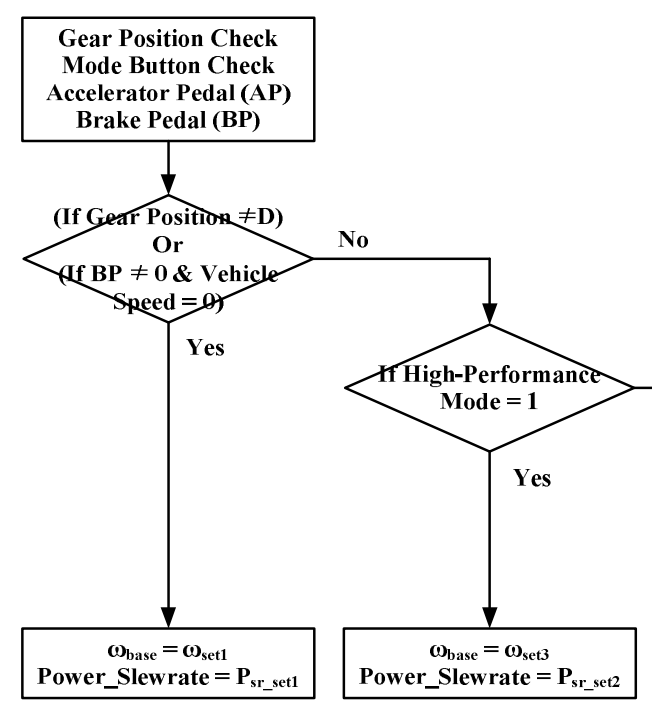

Fig. 7. Operating strategy of the engine-generator(EnGen).

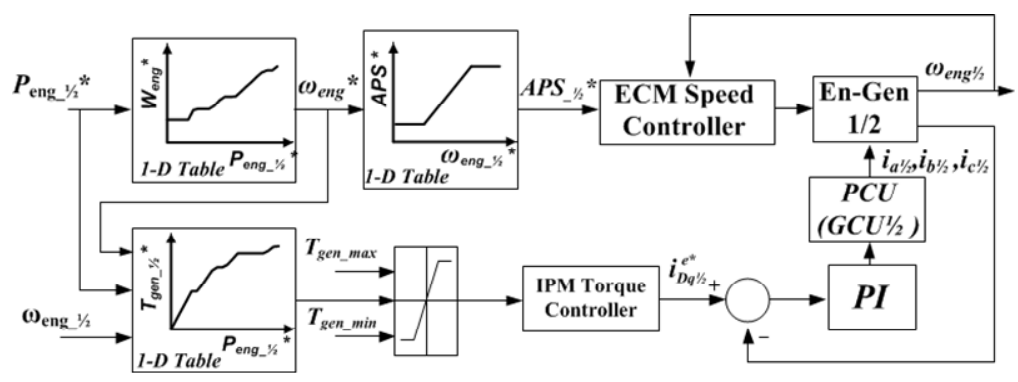

Fig. 8. Control block diagram of the engine-generator.

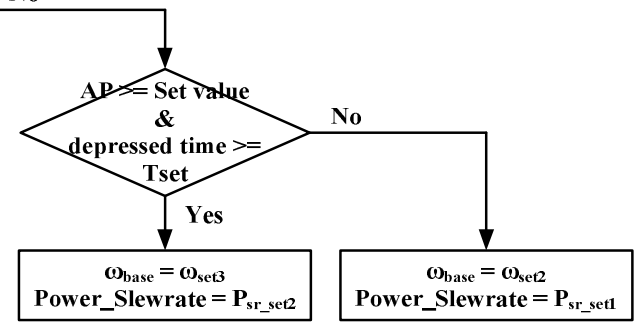

operating line of Fig. 6. In this paper, the feedback method using the output voltage generated by the current controller and the feed-forward method with $\mathrm{d}$ - and q-axis current reference using 2-D dimensional tables are applied in order to control the generator current for the maximum torque per Ampere (MTPA) and field weakening control of the IPM generator [26].

\subsection{Description for the power distribution algorithm}

The power flow of the system has two operating modes. Normally, the IPCU operates according to commands received from the vehicle control unit (VCU) inside the

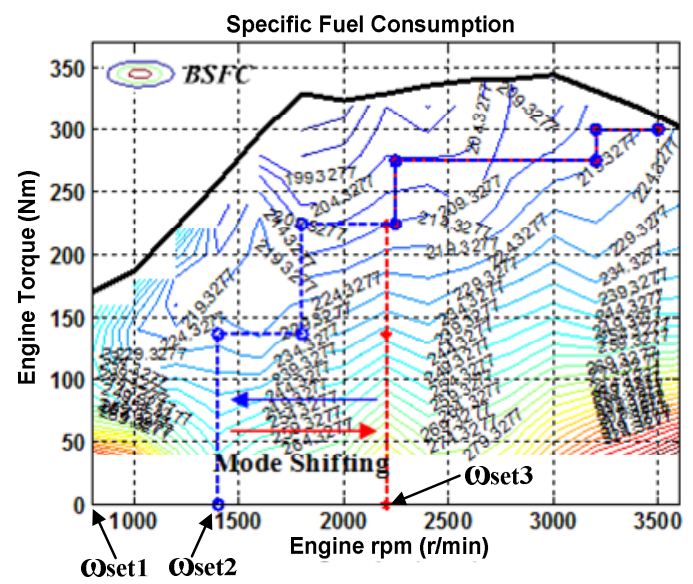

Fig. 6. Engine-generator operating point on the specific fuel consumption map. 
vehicle. Additionally, the IPCU has a stand-alone power control mode in case of communication failure. Fig. 9 shows the power control algorithm for the latter case.

In this paper, an improved power distribution algorithm based on the frequency of the load power is proposed. For the OOL tracking of the EnGen with slow dynamics, the battery and the ultra-capacitor are employed to supply a fast transient power spike to meet the power requirement during acceleration and deceleration of the vehicle. In addition, the ultra-capacitor supplies some portions of the low-pass filtered power required from the ESS when it is operated within the pre-determined SOC. It can be determined by adjusting the coefficient $K_{l p f}$, keeping in mind the system efficiency, the life-time of the battery and the driving performance, as shown in Fig. 9. In this case, the coefficient is chosen to be a ratio of the power ratings

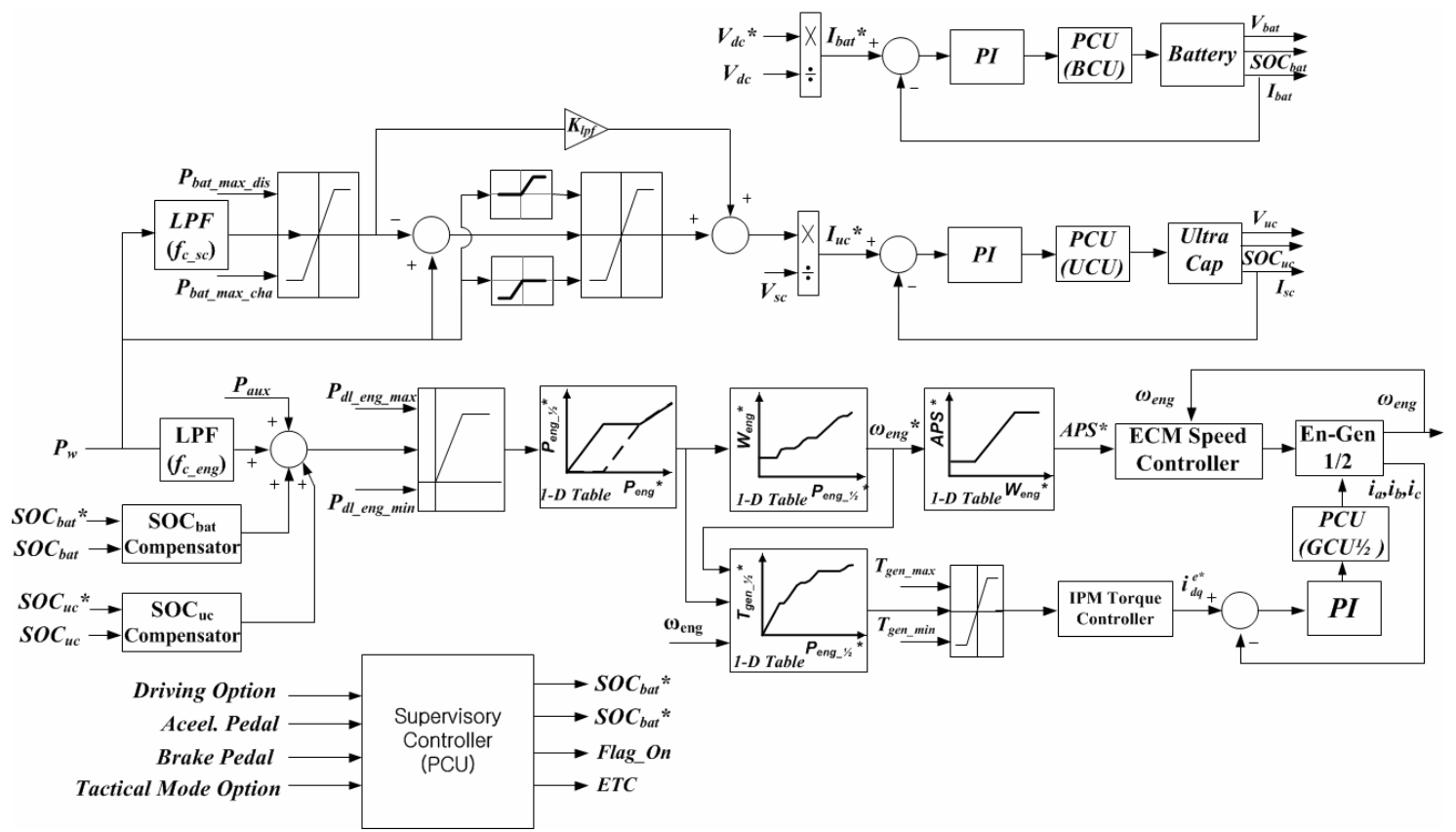

Fig. 9. Power control algorithm of the integrated power control unit (IPCU).

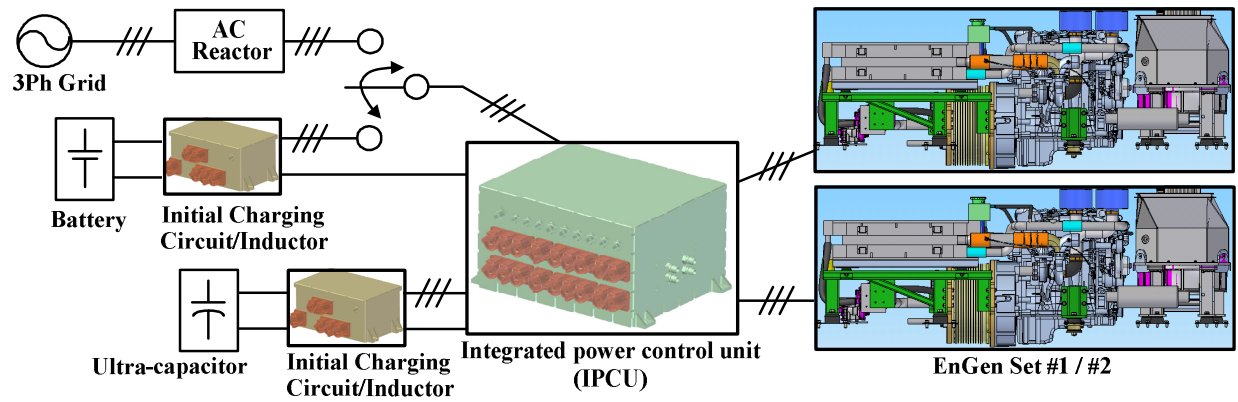

(a)

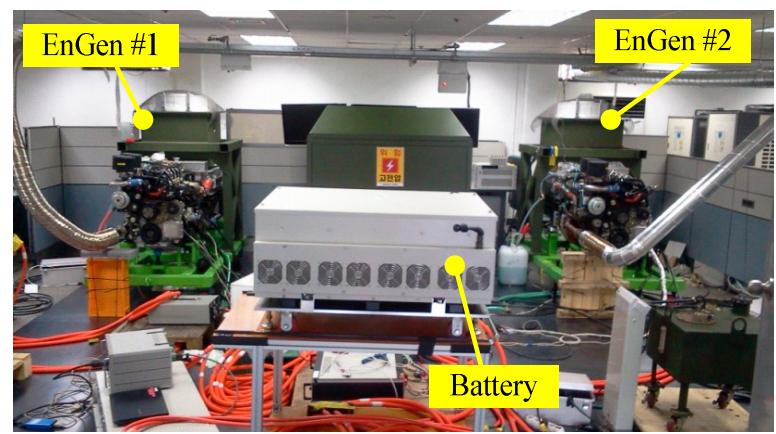

Fig. 10. Experimental configuration of the integrated power control unit (IPCU); (a) Configuration of the experimental set, (b) Hardware of the experiment. 
of the battery and the ultra-capacitor. Some of the parameter settings of Fig. 9 are determined by the supervisory control block in order to achieve the optimal efficiency of the dual EnGen, the management of SOCs of the ESS, and the safe and fault-tree operation of each power converter.

\section{Experimental results}

We conducted experiments in order to verify the performance of the designed IPCU as well as the static and dynamic performance of each power converter while the converters were linked to power source, prior to vehicle assembly. The experimental setup is shown in Fig. 10. The IPCU has in it a grid-connected inverter and an ACDC converter, as shown in Fig. 10. In order to save the development time needed for the verification of the dynamics and for the protection of the integrated converters, the charging and discharging load power is provided by this above-mentioned feature of the IPCU. Various load profiles emulating the road power of the vehicle can therefore be tested in advance, during the development phase itself. Over wide operating ranges, the discharging staircase power of more than $100 \mathrm{~kW}$ is stably controlled through the IPCU. In addition, the staircase discharging power is stably controlled to stay within the operating range of the high voltage battery.

Figs. 11 and 12 show the experimental results of the control functions of the EnGen, collected by the CAN. Fig. 11 represents the results of the engine starting and the speed regulation. At $T_{1}$, the engine ignition command, denoted as the Flag_Eng, is issued and the monitoring torque from a generator is exerted o $\mathrm{n}$ the engine. At $\mathrm{T}_{2}$, after completing the engine startup, the speed for the EnGen is regulated to an idle speed by the ECM. Subsequently, the engine speed is fully regulated to its maximum value from $\mathrm{T}_{3}$ to $\mathrm{T}_{4}$ under a no-load condition. Fig. 12(a) shows the generated power regulation results from the EnGen. The accuracy error of the generated

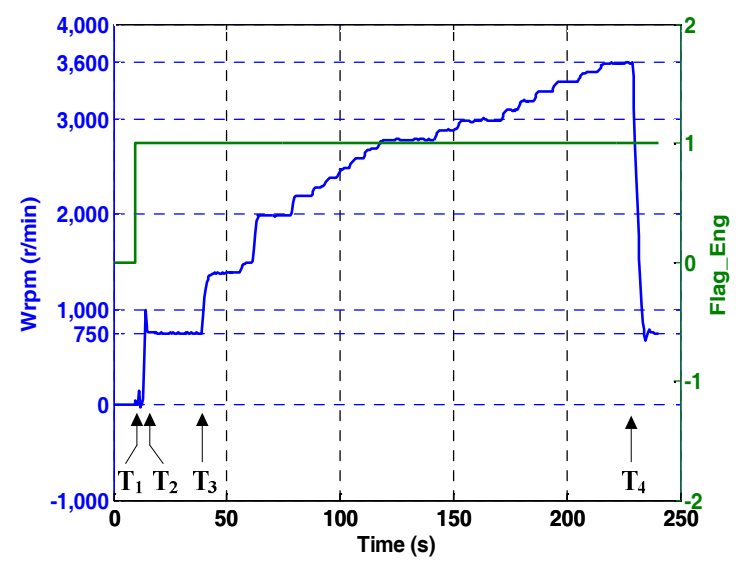

Fig. 11. Engine starting and speed regulation result.

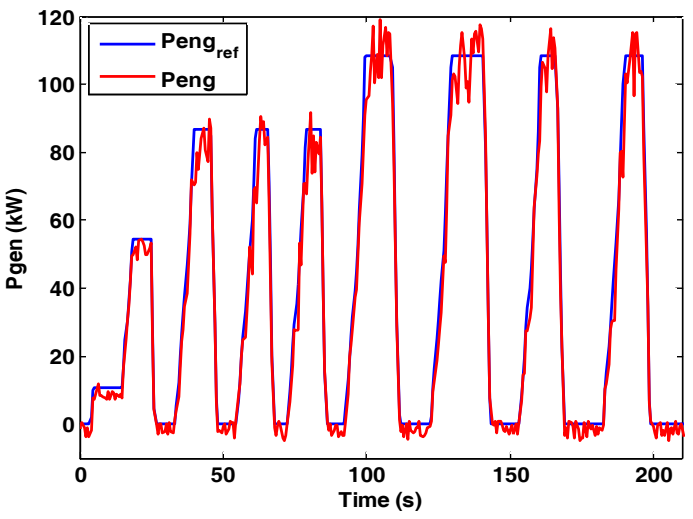

(a)

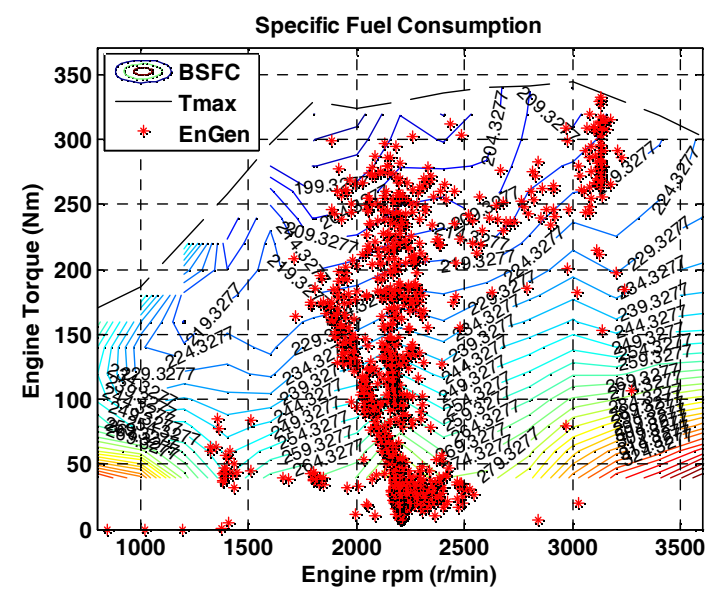

(b)

Fig. 12. Power generation characteristics of the EnGen; (a) Tracking performance of the generated power of the EnGen, (b) Operating points of the EnGen.

power compared to the reference power is within $\pm 5 \%$, and the dynamic characteristic of the EnGen is programmed to be $0.2 \sim 0.3$ per-unit second for the case of the per-unit value being based on the maximum power of the engine. In addition, Fig. 12(b) shows the operating points of the EnGen on the speed-torque plane obtained from the experimental illustrated in Fig. 12(a). We can see that the EnGen was operating at close to the pre-determined operating points, considering the efficiency and dynamics as shown in the red line in Fig. 6.

As mentioned previously, the IPCU developed here is installed and utilized as the power control device in the SHEV. Fig. 13 shows the experimental result for the acceleration performance during the drive test of the pilot vehicle. With a fully depressed accelerator pedal, the power outputs of the 4-power sources and the loads, including the traction, steering, and cooling, are well balanced by the proposed power distribution algorithm, as shown in Fig. 13(a). Also from Figs. 13(b) through (e), we can see that the DC-link voltage is stably regulated to a rated voltage, $640 \mathrm{Vdc}$, and the voltages and SOCs of the battery and ultra-capacitor are held within the pre-determined stable 


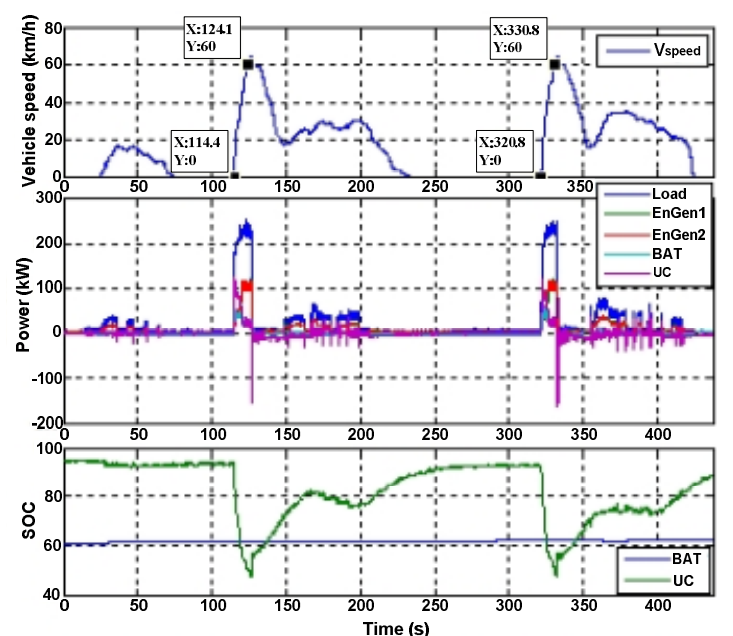

(a)

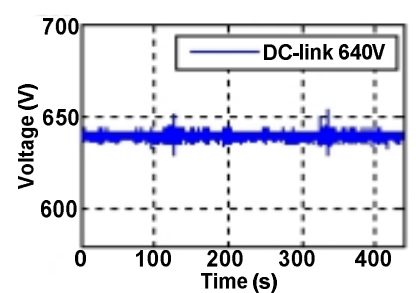

(b)

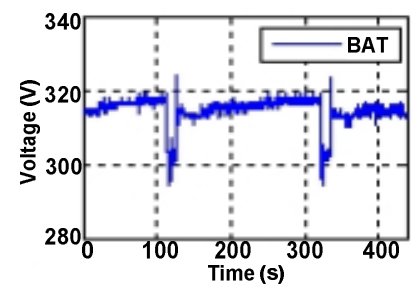

(d)

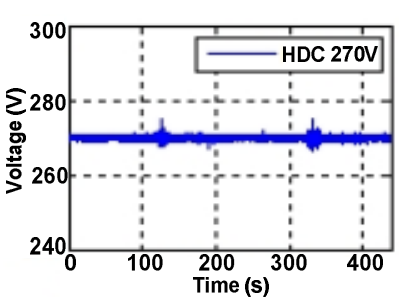

(c)

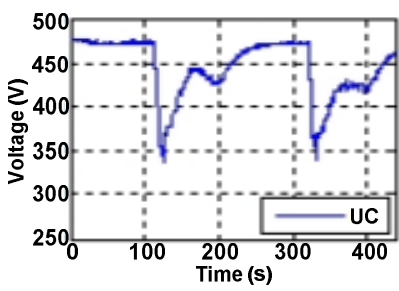

(e)
Fig. 13. Vehicle-level experimental results during the maximum acceleration driving test; (a) Power and energy distribution results, (b) DC-link voltage result. (c) HDC voltage result, (d) Battery voltage result, (e) Ultra-capacitor voltage result.

operating regions.

\section{Conclusion}

In order to satisfy a power control unit with high power density and reliable control operation, the SHEV generally have multiple power sources such as an EnGen, a battery, an ultra-capacitor. However, manufacturing using separate individual power converters has the drawbacks of low power density and requires a great of power and signal cable wires. Moreover, because of the communication delay between the units, it is also difficult to implement the optimal power distribution and fault management algorithm. Therefore, in this work, the design methodology and power control algorithm of an integrated power control unit of the SHEV powered by multiple power sources are proposed. Through integration of the control boards and power stages that replace multiple power converters, it is possible to achieve optimal and reliable power distribution as well as a high power density of the power converter. Consequently, the manufactured device is verified through product-level and vehicle-level experimental tests on a 10ton SHEV.

\section{Acknowledgements}

This work was supported by a research fund from Chosun University, 2014

\section{References}

[1] Katrašnik T. Analytical method to evaluate fuel consumption of hybrid electric vehicles at balanced energy content of the electric storage devices. Appl Energy 2010; 79:51-64.

[2] Wang L, Cheng Y, Zou J. Battery available power prediction of hybrid electric vehicle based on improved Dynamic Matrix Control algorithms. J Power Sources 2014; 261:337-347.

[3] Waag W, Fleischer C, Sauer DU. Critical review of the methods for monitoring of lithium-ion batteries in electric and hybrid vehicles. J Power Sources 2014; 258:321-339.

[4] Miliani EH. Leakage current and commutation losses reduction in electric drives for Hybrid Electric Vehicle. J Power Sources 2014; 255:266-273.

[5] Chen Z, Mi CC, Xiong R, Xu J, You C. Energy management of a power-split plug-in hybrid electric vehicle based on genetic algorithm and quadratic programming. J Power Sources 2014; 248:416-426.

[6] Torres JL, Gonzalez R, Gimenez A, Lopez J. Energy management strategy for plug-in hybrid electric vehicles. A comparative study. Appl Energy 2013; 114:816-824.

[7] Wu X, Cao B, Li X, Xu J, Ren X. Component sizing optimization of plug-in hybrid electric vehicles. Appl Energy 2011; 88:799-804.

[8] Han J, Park Y, Kim D. Optimal adaptation of equivalent factor of equivalent consumption minimization strategy for fuel cell hybrid electric vehicles under active state inequality constraints. J Power Sources 2014; 267:491-502.

[9] Xu L, Li J, Ouyang M, Hua J, Yang G. Multi-mode control strategy for fuel cell electric vehicles regarding fuel economy and durability. Int $\mathrm{J}$ Hydrog Energy 2014; 39:2374-2389.

[10] Xu L, Ouyang M, Li J, Yang F, Lu L, Hua J. Optimal sizing of plug-in fuel cell electric vehicles using models of vehicle performance and system cost. Appl 
Energy 2013; 103:477-487.

[11] Chopra S, Bauer P. Driving Range Extension of EV With On-Road Contactless Power Transfer-A case Study. IEEE Trans Ind Electron. 2013; 60 (1): 329338.

[12] Muñoz-Condes P, Gomez-Parra M, Sahcho C, Andrés MAGS, González-Fernández FJ, Carpio J, Guirado RU. On Condition Maintenance Based on the Impedance Measurement for Traction Batteries: Development and Industrial Implementation. IEEE Trans Ind Electron. 2013; 60 (7):2750-2759.

[13] KIM SI, Park S, Park T, Cho J, Kim W, Lim S. Investigation and Experimental Verification of a Novel Spoke-Type Ferrite-Magnet Motor for ElectricVehicle Traction Drive Applications. IEEE Trans Ind Electron. 2014; 61 (10):5763-5770.

[14] Tong C, Zheng P, Wu Q, Bai J, Zhao Q. A Brushless Claw-Pole Double-Rotor Machine for Power-Split Hybrid Electric Vehicles. IEEE Trans Ind Electron. 2014; 61 (8):4295-4305.

[15] Hu Y, Song X, Cao W, Ji B. New SR Drive With Integrated Charging Capacity for Plug-ion Hybrid Electric Vehicles (PHEVs). IEEE Trans Ind Electron. 2014; 61 (10):5722-5731.

[16] Nian X, Peng F, Zhang H. Regenerative Braking System of Electric Vehicle Driven by Brushless DC Motor. IEEE Trans Ind Electron. 2014; 61 (10): 5798-5808.

[17] Lukic SM, Wirasingha SG, Rodriguez F, Cao J, Emadi A. Power Management of an Ultracapacitor/ Battery Hybrid Energy Storage System in an HEV. IEEE Vehicle Power and Propulsion Conference (VPPC). 2006.

[18] Dixon J, Nakashima I, Arcos EF, Ortuzar M. Electric Vehicle Using a Combination of Ultracapacitors and ZEBRA Battery. IEEE Trans Ind Electron. 2010; 57 (3):943-949.

[19] Gao L, Dougal RA, Liu S. Active power sharing in hybrid battery/capacitor power sources. IEEE Applied Power Electronics Conference and Exposition (APEC). 2003.

[20] Erickson RW, Maksimovic D. Fundamental of Power Electronics. $2^{\text {nd }}$ Edition. Kluwer Academic Publishers. 2001.

[21] Infineon, IPOSIM, https://infineon.transim.com/iposim

[22] Semikron, Semisel Simulation, https://infineon.transim.com/iposim

[23] Maksimovic D, Zane R. Small Signal Discrete-time Modeling of Digitally Controlled DC-DC Converters. IEEE COMPEL Workshop. 2006.

[24] Kim JW, Choi HS, Cho BH. A Novel Droop Method for Converter Parallel Operation. IEEE Trans Power Electron. 2002; 17 (1):25-32.

[25] Middlebrook RD. Small-signal modeling of pulsewidth modulated switch-mode power converters. Proceedings of the IEEE. 1988; 76 (4):343-354.
[26] Bae BH, Sul SK. A Novel Dynamic Overmodulation Strategy for Fast Torque Control of High-SaliencyRatio AC Motor. IEEE Trans Ind Appl. 2005; 41 (4):1013-1019.

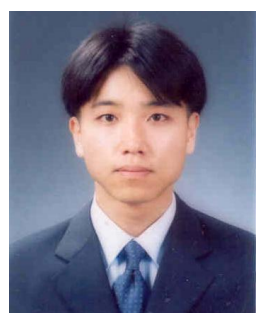

Seongjun Lee $\mathrm{He}$ received received the B.S. degree in electrical engineering from Kwangwoon University, Seoul, Korea, in 2004, and the M.S. and Ph.D. degrees from Seoul National University, Seoul, Korea, in 2006 and 2011, respectively. From 2011 to 2014 he was working as a Senior Research Engineer in Defence Program Division, Samsung Techwin, Seongnam, Korea. He is currently a Senior Research Engineer at Hyundai MOBIS, Yongin, Korea. His main research interests include design, analysis, modeling and control of power electronics for hybrid electric vehicle and electric vehicle, battery management system (BMS), and distributed power system. Dr. Lee is a member of the Korean Institute of Power Electronics.

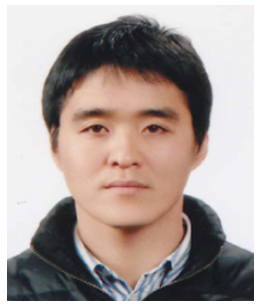

Jonghoon Kim He received the B.S. degree in Electrical Engineering from Chungnam National University, Daejeon, Republic of Korea and Ph.D degrees in Electrical Engineering and Computer Science from Seoul National University, Republic of Korea, in 2005 and 2012, respectively. From 2012 to 2013, he was a Senior Research Engineer in Energy Storage System (ESS) Development Group, Energy Solution (ES) Division, Samsung SDI, Cheonnan, Republic of Korea. He is currently an assistant professor with the Department of Electrical Engineering, Chosun University, Gwangju, Republic of Korea. His main research interests include battery management system (BMS; modelling, screening, equalization, SOC/SOH estimation), Lithium-air, and fuel cell system (ripple current analysis, fault diagnosis, $\mathrm{SOH}$ prediction, and modelling). He is a member of IEEE and the Korean Institute of Power Electronics (KIPE). In addition, he is currently an Associate Editor of the Journal of Power Electronics (JPE). He received the Student Paper Award from IPEC-10. 